\title{
Therapeutic potential of targeting cell division cycle associated 5 for oral squamous cell carcinoma
}

\author{
Norihiko Tokuzen ${ }^{1}$, Koh-ichi Nakashiro ${ }^{1}$, Hiroshi Tanaka ${ }^{1}$, Kazuki Iwamoto ${ }^{1}$ and \\ Hiroyuki Hamakawa ${ }^{1}$ \\ ${ }^{1}$ Department of Oral and Maxillofacial Surgery, Ehime University Graduate School of Medicine, Shitsukawa, Toon, Ehime, \\ Japan \\ Correspondence to: Koh-ichi Nakashiro, email: nakako@m.ehime-u.ac.jp
}

Keywords: cell division cycle associated 5 (CDCA5), oral squamous cell carcinoma (OSCC), cell cycle, prognosis, molecular targeted therapy

Received: July 02, $2015 \quad$ Accepted: September 30, $2015 \quad$ Published: October 19, 2015

This is an open-access article distributed under the terms of the Creative Commons Attribution License, which permits unrestricted use, distribution, and reproduction in any medium, provided the original author and source are credited.

\section{ABSTRACT}

Molecularly targeted drugs are used in the treatment of a variety of malignant tumors, but this approach to developing novel therapies for oral squamous cell carcinoma (OSCC) has lagged behind the progress seen for other cancers. We have attempted to find appropriate molecular targets for OSCC and identified cell division cycle associated 5 (CDCA5) as a cancer-related gene which was overexpressed in all the human OSCC cells tested by microarray analysis. In this study, we investigated the expression and function of CDCA5 in OSCC. First, we confirmed that CDCA5 was overexpressed in 4 human OSCC cell lines by quantitative RT-PCR and Western blotting. We then tested the effect of synthetic small interfering RNAs specific for CDCA5 on the growth and invasion of human OSCC cells. Knockdown of CDCA5 markedly inhibited the growth of OSCC cells in vitro and in vivo. We also examined the expression of CDCA5 protein in 80 cases of OSCC immunohistochemically and found a significant association between CDCA5 expression levels and overall survival. These results suggest that CDCA5 functions as a critical gene supporting OSCC progression and that targeting CDCA5 may be a useful therapeutic strategy for OSCC.

\section{INTRODUCTION}

Oral squamous cell carcinoma (OSCC) is estimated 263,000 new cases and 127,000 deaths in 2008 worldwide [1]. OSCC has a high potential to invade local tissue and metastasize to lymph nodes, and has a mortality rate of approximately 50\% within 5 years [2]. Despite our increasing knowledge of OSCC pathogenesis and advances in chemotherapy, radiotherapy, and surgery, little improvement in the relative survival rate of patients with OSCC has been observed in the past several decades [2]. Therefore, novel strategies based on a greater understanding of the pathogenesis of OSCC are needed for the development of improved therapeutic approaches.

Cancer cells acquire abnormalities in multiple oncogenes and tumor-suppressor genes. Overexpression and constitutive activation of some of these oncogenes support the proliferation, invasion, and metastasis of cancer cells. However, this dependence on oncogenes for maintaining the cancer phenotype also provides molecular targets, which can be exploited in cancer therapy [3]. Recent studies of human malignancies have shown that it is possible to use pharmacological agents that inactivate oncogenes to treat some types of human cancer. For example, imatinib, which targets breakpoint cluster region-abelson (BCR-ABL), is used to treat patients with chronic myelogenous leukemia [4] and crizotinib, which targets anaplastic lymphoma kinase (ALK), is used to treat patients with ALK-positive non-small cell lung cancer [5]. Although targeting oncogenes in this way has provided novel therapeutic opportunities, the development of molecular targeted therapy for OSCC has lagged behind other cancers. Therefore, we have attempted to identify appropriate molecular targets for OSCC. In a previous study, we used microarray analysis and Ingenuity Pathway Analysis (IPA) to identify 465 cancer-related genes that were overexpressed in all the human OSCC cell lines examined [6]. Among these genes, we identified cell 
Table 1: Association between CDCA5 expression in tumors from OSCC patients and their clinicopathological parameters

\begin{tabular}{|c|c|c|c|}
\hline Parameter & $\begin{array}{c}\text { Low CDCA5 } \\
(n=40) \\
\text { Number }(\%)\end{array}$ & $\begin{array}{c}\text { High } \\
\text { CDCA5 } \\
(n=40) \\
\text { Number }(\%)\end{array}$ & $p$ value \\
\hline \multicolumn{4}{|l|}{ Sex } \\
\hline Male & $23(57.5)$ & $23(57.5)$ & 1 \\
\hline Female & $17(42.5)$ & $17(42.5)$ & \\
\hline \multicolumn{4}{|l|}{ Primary tumor site } \\
\hline Tongue & $17(42.5)$ & $14(35)$ & 0.25 \\
\hline Maxillary gingiva & $7(17.5)$ & $5(12.5)$ & \\
\hline Mandibular gingiva & $9(22.5)$ & $14(35)$ & \\
\hline Floor of mouth & $1(2.5)$ & $4(10)$ & \\
\hline Buccal mucosa & $5(12.5)$ & $3(7.5)$ & \\
\hline Lower lip & $1(2.5)$ & $0(0)$ & \\
\hline \multicolumn{4}{|l|}{ Differentiation } \\
\hline Well & $33(82.5)$ & $24(60)$ & 0.05 \\
\hline Moderate & $6(15)$ & $10(25)$ & \\
\hline Poor & $1(2.5)$ & $6(15)$ & \\
\hline \multicolumn{4}{|l|}{ TNM stage } \\
\hline Stage I, II & $24(60)$ & $18(45)$ & 0.262 \\
\hline Stage III, IV & $16(40)$ & $22(55)$ & \\
\hline \multicolumn{4}{|l|}{ Recurrence/Metastasis } \\
\hline No & $27(67.5)$ & $18(42.9)$ & 0.070 \\
\hline Yes & $13(32.5)$ & $22(57.1)$ & \\
\hline Local recurrence & $3(7.5)$ & $10(25)$ & 0.069 \\
\hline Lymph node metastasis & $6(15)$ & $7(17.5)$ & 1 \\
\hline Distant metastasis & $4(10)$ & $5(12.5)$ & 1 \\
\hline
\end{tabular}

division cycle associated 5 (CDCA5) as a substrate of the anaphase-promoting complex (APC) and as a regulator of sister chromatid cohesion in HeLa cells [7-9]. CDCA5 protein is degraded through Cdc20 homolog 1 (Cdh1)activated $\mathrm{APC}\left(\mathrm{APC}^{\mathrm{cdh} 1}\right)$-dependent ubiquitination in the G1 phase and is required for sister chromatid cohesion in the S and G2 phases [7]. Furthermore, CDCA5 has been reported to be overexpressed in the majority of human lung cancers and urothelial cancers and to play a critical role in carcinogenesis [10-13].

In this study, we investigated the expression and function of CDCA5 in OSCC to clarify whether targeting
CDCA5 is likely to be a promising strategy for the treatment of OSCC.

\section{RESULTS}

\section{Overexpression of CDCA5 in human OSCC cells}

We confirmed the expression of CDCA5 mRNA in 4 human OSCC cell lines (green fluorescent protein (GFP)$\mathrm{SAS}, \mathrm{Ca9}-22$, HSC2, and $\mathrm{HSC} 3$ ) by real-time quantitative 
RT-PCR (qRT-PCR). High levels of CDCA5 mRNA expression were observed in all OSCC cell lines compared with the human immortalized non-neoplastic keratinocyte cell line, HaCaT (Figure 1A). Subsequently, we examined the expression levels of CDCA5 protein by Western blot analysis and detected its abundant expression in OSCC cells, whereas its expression was hardly detectable in HaCaT cells (Figure 1B). These results showed that both CDCA5 mRNA and protein were overexpressed in human OSCC cells.

\section{Effect of CDCA5 suppression on the growth of human OSCC cells in vitro}

We clarified the function of CDCA5 in the proliferation and invasiveness of human OSCC cells, by transfecting them with synthetic small interfering RNA (siRNA) specific for CDCA5 (siCDCA5) at a concentration of $10 \mathrm{nM}$. Synthetic siCDCA5 suppressed the expression of CDCA5 protein (Figure 2A). When we then examined the effect of siCDCA5 on the growth and invasion of human OSCC cells, we found that CDCA5 knockdown significantly inhibited cell growth by 50 $81 \%$ (Figure 2B) but not invasiveness (data not shown), compared to an untargeted siRNA (siNT).

\section{Role of CDCA5 in the cell cycle in human OSCC cells}

CDCA5 has been reported to have an important role in the cell cycle [7-9]. We therefore analyzed the effect of siCDCA5 on the cell cycle by flow cytometry using GFP-SAS cells. After the cells had been treated with 10 nM siCDCA5 for $48 \mathrm{~h}$, significantly fewer cells were in G0/G1 phase and significantly more were in G2 phase, compared to cells treated with siNT (Figure 3A, 3B). The data indicated that the anti-proliferative effect of siCDCA5 was due to an arrest in G2. Ca9-22, HSC2, and HSC3 cells also showed the similar results (data not shown).

\section{Effect of siCDCA5 on the in vivo growth of human OSCC cells}

We assessed the growth inhibitory effect of siCDCA5 in vivo using a mouse model. We used GFPSAS cells for this in vivo assay because only these cells, of the four lines we used, showed stable tumorigenicity. We administered siCDCA5/atelocollagen complexes into the subcutaneous spaces around the tumors every 3 days. We found that these complexes significantly reduced the size of subcutaneously xenografted GFP-SAS tumors, compared with the control group treated with synthetic siRNA specific for GFP (siGFP)/atelocollagen complexes (Figure 4A). Furthermore, the expression of CDCA5 in excised tumor tissue was markedly suppressed, by $53 \%$, in the group treated with siCDCA5 (Figure 4B). During the administration of siCDCA5, no reduction in either food intake or body weight was seen in the mice. We also examined the expression of interferon response genes such as interferon stimulated gene factor $3 \gamma$ (ISGF-3 $\gamma$ ), 2', 5'-oligoadenylate synthetase 2 (OAS2), and interferoninduced myxovirus resistance protein 1 (MX1) in liver and lung tissues from mice by qRT-PCR. There was no significantly induction of these genes by treatment with siGFP or siCDCA5/atelocollagen complex (data not shown).

\section{Effect of targeting CDCA5 in primary human OSCC cultured cells}

To confirm the usefulness of targeting CDCA5 in OSCC, we established primary cell cultures from newly resected tumor tissues from patients with OSCC. These primary cultured cells were derived from two lower gingival tumors, a lymph node metastasis, and a skin metastasis. When we tested the effect of siCDCA5 on

A

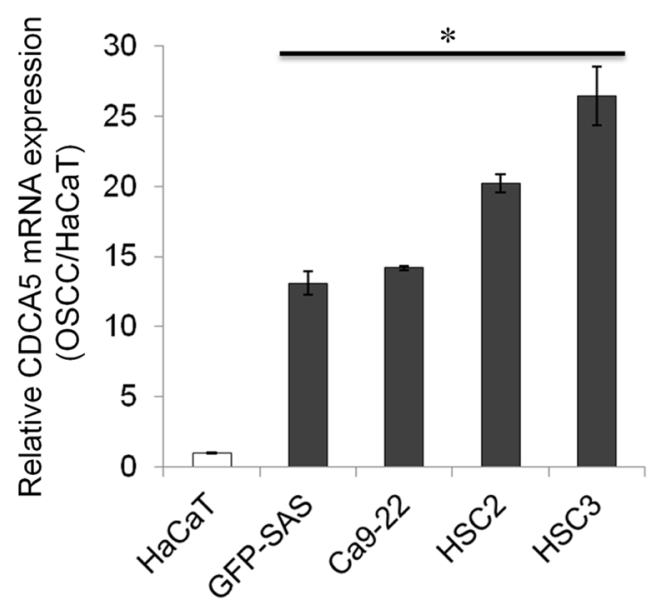

B

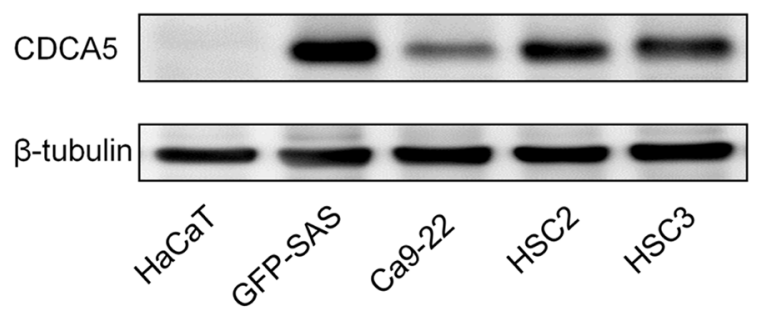

Figure 1: Overexpression of CDCA5 in human OSCC cells. A. Expression of CDCA5 mRNA in 4 human OSCC cell lines and a human immortalized non-neoplastic keratinocyte cell line $(\mathrm{HaCaT})$ was evaluated by qRT-PCR. Expression levels are shown relative to $\mathrm{HaCaT}$ cells. ${ }^{*}, p<0.01$ compared to HaCaT. B. Western blots showing the expression of CDCA5 protein compared to $\beta$-tubulin in OSCC cells. 
A

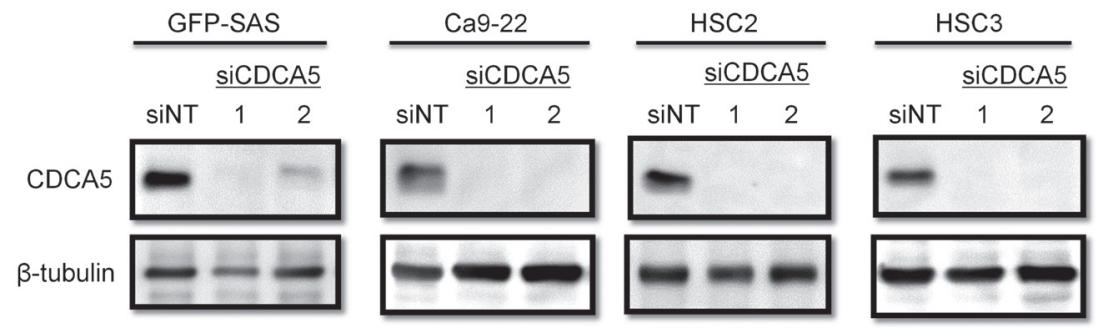

B

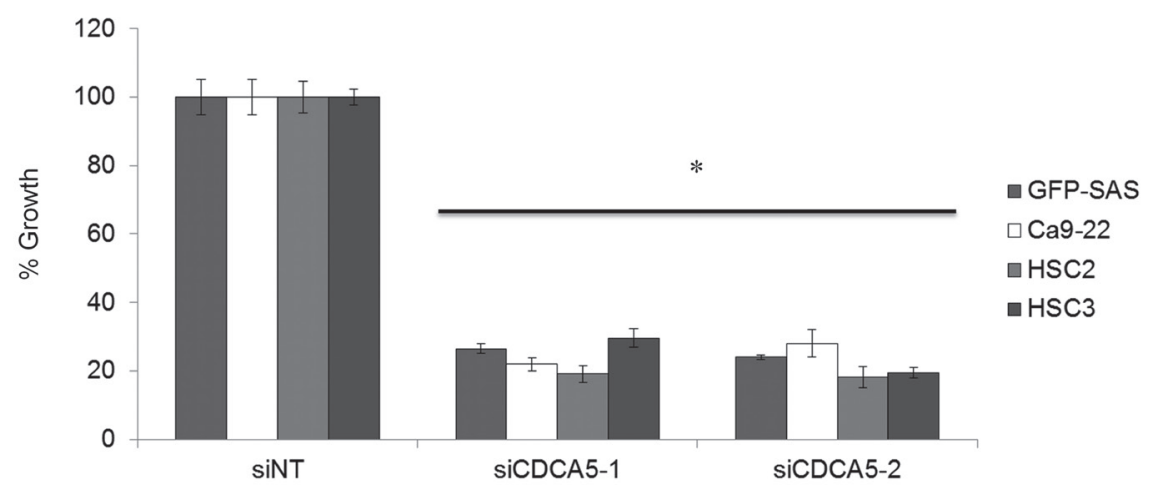

Figure 2: Knockdown of CDCA5 in human OSCC cells by siRNA. A. Western blots showing the effect of RNAi on CDCA5 expression. Two different siCDCA5s at $10 \mathrm{nM}$ were transfected into human OSCC cell lines GFP-SAS, Ca9-22, HSC2, and HSC3 with Lipofectamine RNAiMAX. B. The effect of transfecting siCDCA5 into human OSCC cell lines on their growth, evaluated using WST-8 assays. ${ }^{*}, p<0.01$ Growth is expressed relative to the same cell cultures transfected with an untargeted, siNT.

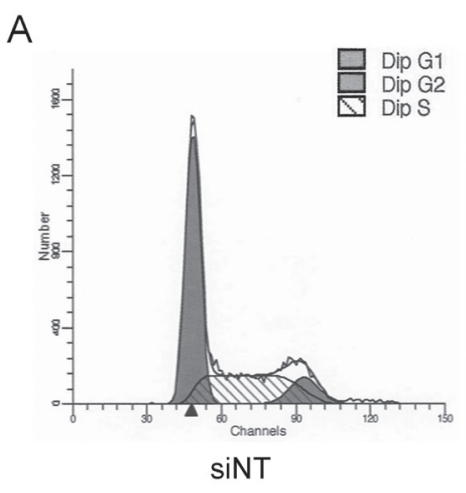

$\mathrm{B}$

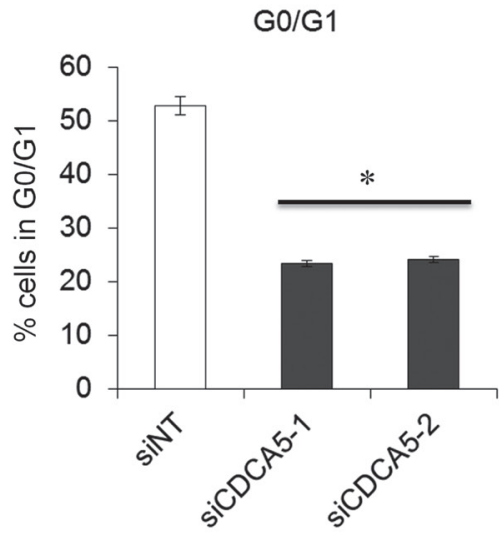

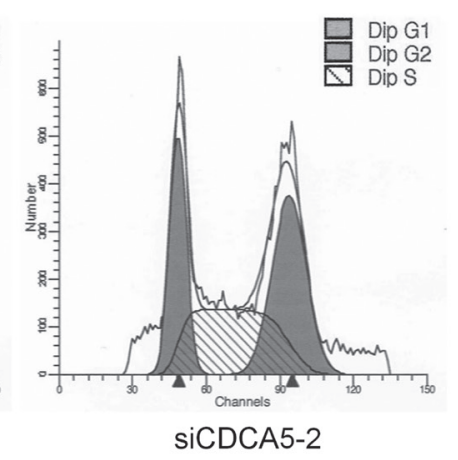

G2

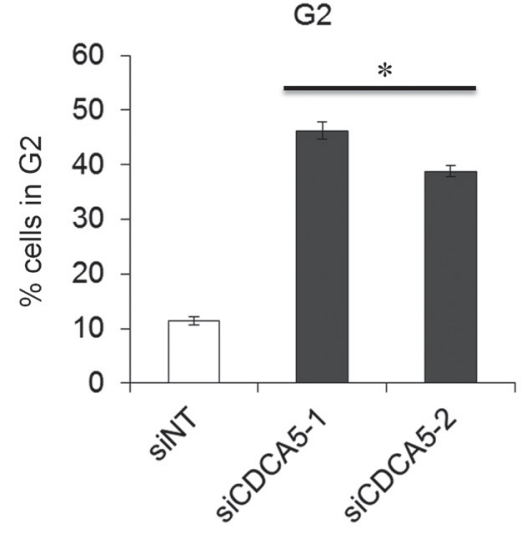

Figure 3: Role of CDCA5 in the cell cycle of human OSCC cells. A. Flow cytometry profiles showing numbers of GFP-SAS cells in $\mathrm{G} 1, \mathrm{G} 2$, and $\mathrm{S}$ phase $48 \mathrm{~h}$ after transfection with different siRNAs at $10 \mathrm{nM}$. B. Histograms showing the percentage of GFP-SAS cells in different stages of the cell cycle $48 \mathrm{~h}$ after transfection with siRNAs. ${ }^{*}, p<0.01$ compared to control culture. 
these primary cultures, as with the established human OSCC cell lines, siCDCA5 suppressed protein expression in all four primary cultures (Figure 5A) and inhibited the growth of these cells by $67-139 \%$, compared to cells

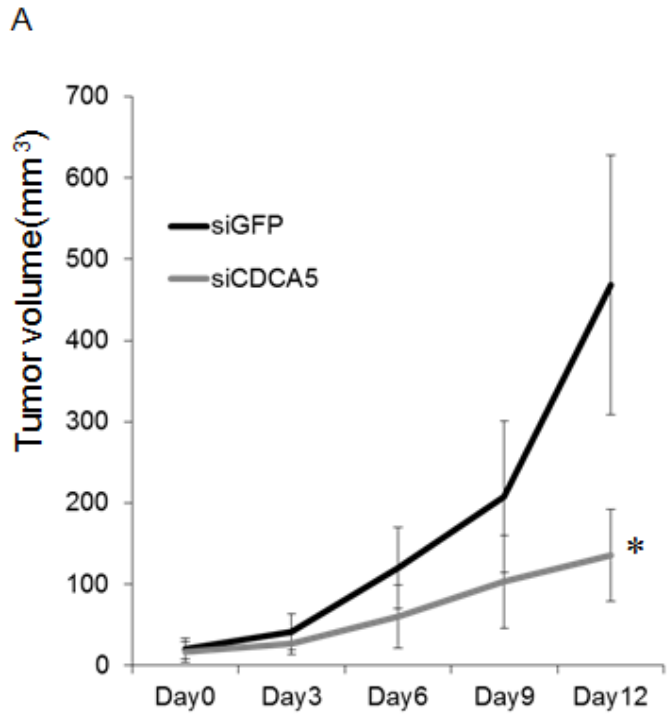

treated with siNT (Figure 5B).

B
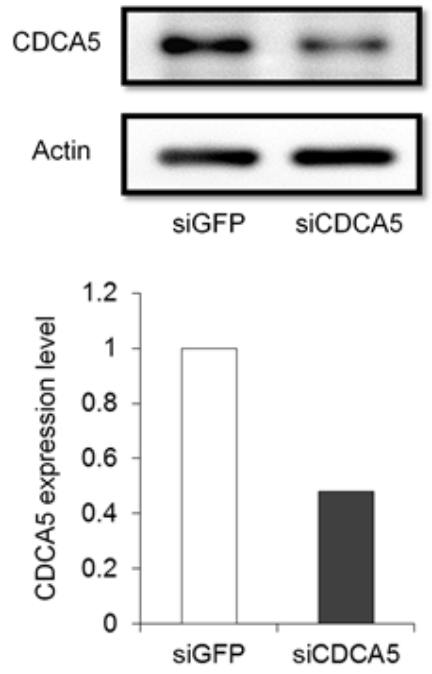

Figure 4: Effect of siCDCA5 on the in vivo growth of human OSCC cells. A. GFP-SAS cells at $2 \times 10^{6} / 50 \mu 1$ were injected subcutaneously into the flanks of nude mice with an equal volume of Matrigel $^{\circledR}$. Synthetic siCDCA5/atelocollagen complexes were injected around the tumor every 3 days. Tumor growth was measured and volumes calculated until the tumors were excised on day $13 . *, p<$ 0.01 compared to control culture. B. CDCA5 protein expression was assessed in excised tumors by Western blotting (upper panel) and densitometry (lower panel).

A OSCC primary cultured cells
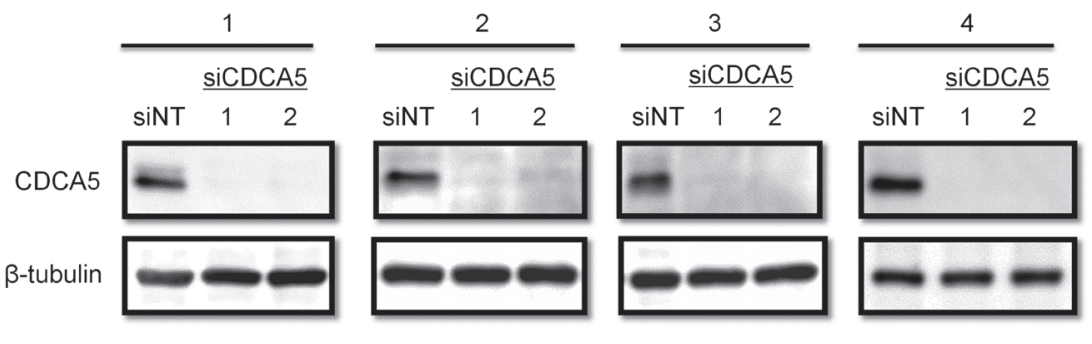

B

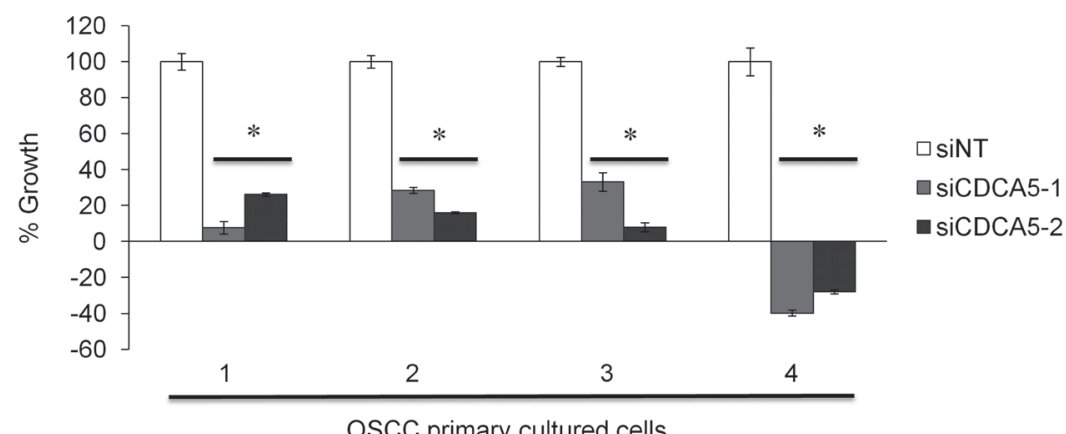

Figure 5: Effect of targeting CDCA5 in human OSCC primary cell cultures. A. OSCC primary cultured cells were derived from lower gingiva of 55 year-old male (1), lymph node metastasis of 55 year-old male (2), lower gingiva of 80 year-old female (3), and skin metastasis of 61 year-old male (4), respectively. These cells were transfected with $10 \mathrm{nM}$ siCDCA5 in Lipofectamin RNAiMAX. The effects of RNAi were analyzed by Western blotting. B. Cell growth was evaluated $72 \mathrm{~h}$ after transfection using WST- 8 assays. *, $p<0.01$ compared to control cultures. 


\section{Clinical significance of CDCA5 expression in OSCC}

To clarify the clinical significance of CDCA5 expression, we examined the expression of CDCA5 in OSCC tissue $(n=20)$. The expression of CDCA5 mRNA in tumor and adjacent normal tissue derived from the same patient was examined by qRT-PCR. Expression levels of CDCA5 mRNA in OSCC tissue were significantly higher than in normal tissue (Figure 6A). We examined CDCA5 protein expression in normal oral mucosa and OSCC tissue immunohistochemically. Most of the CDCA5 expression in OSCC tissues was observed in tumor cells but not stromal cells. In normal tissues, CDCA5 expression was also detected in few lymphocytes (Figure 6B).

We also evaluated the association between CDCA5 expression, assessed immunohistochemically, in tumors from 80 OSCC patients and their clinicopathological parameters. We categorized CDCA5 expression as high or low by the median value of positive rate of tumor cells, and then examined the association between CDCA5 expression and the clinicopathological parameters of the
A

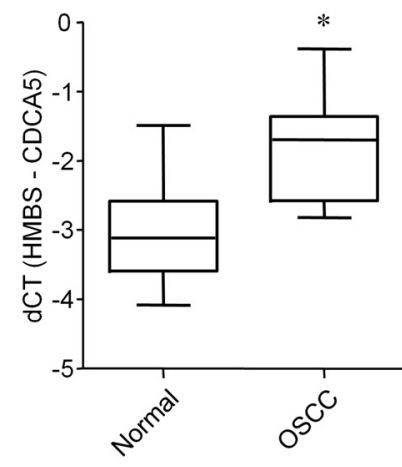

B

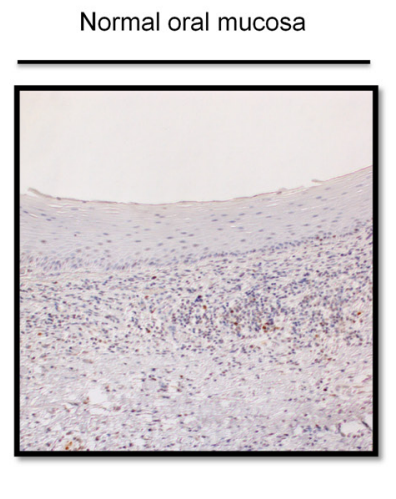

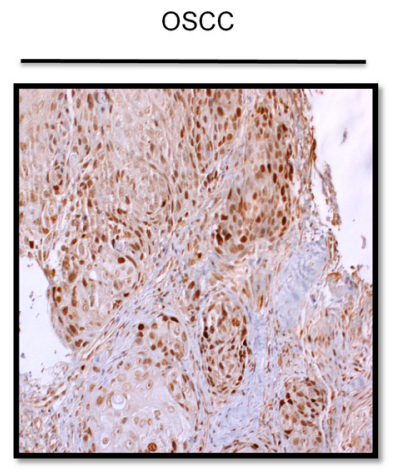

Figure 6: Expression of CDCA5 in OSCC tissue. A. The expression of CDCA5 mRNA in OSCC tumors and the adjacent normal tissue from the same patient $(\mathrm{n}=20)$ was analyzed by qRT-PCR using the comparative CT method and HMBS as the internal control. *, $p<0.01$ compared to normal tissues. B. Sections of normal oral mucosal tissue (left panel) and OSCC tissue (right panel) labelled immunohistochemically for CDCA5 protein.

A

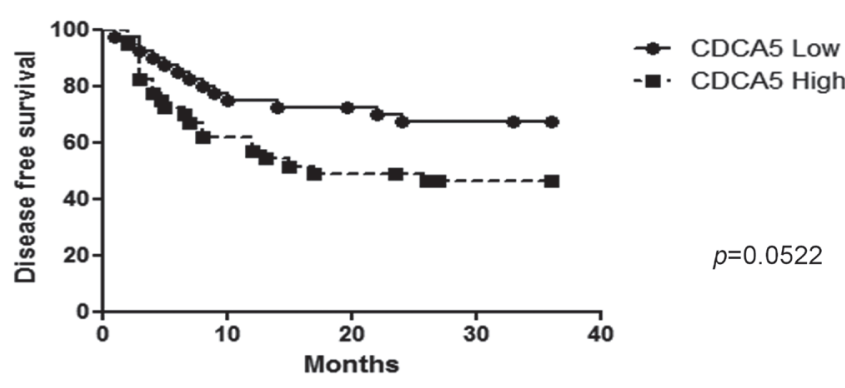

B

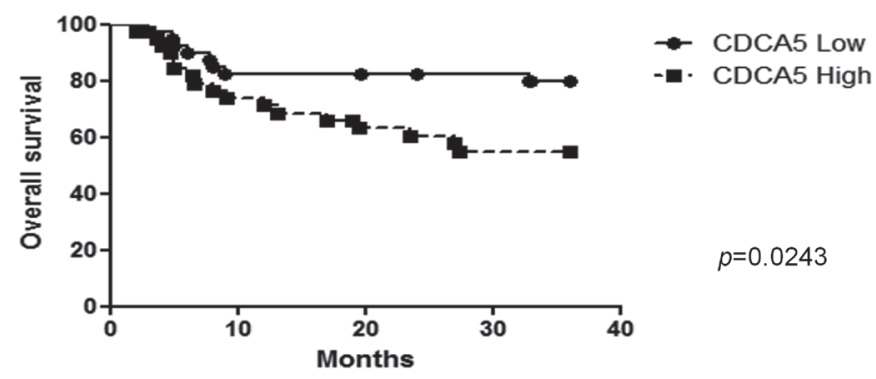

Figure 7: Association between CDCA5 expression level and prognosis. Kaplan-Meier analysis of disease-free survival A. and overall survival B. over 3 years for patients with OSCC tumors expressing high or low CDCA5 levels. 
OSCC patients. Although no significant relationship was observed, high CDCA5 expression tended to be correlated with local recurrences (Table 1). Furthermore, when we examined the association between CDCA5 expression and survival by Kaplan-Meier analysis, we found that high CDCA5 expression was associated with a poor prognosis (Figure 7A, 7B).

\section{DISCUSSION}

Although CDCA5 has been reported to have roles in cell cycle progression in a variety of immortalized cell lines, through its interaction with cohesin on chromatin [8, 9], there is only one report that has investigated its possible role in carcinogenesis, in lung cancer [11]. High CDCA5 expression in lung cancer showed a significant association with a poor prognosis for patients and also promoted cell proliferation. In addition, CDCA5 was shown to be phosphorylated by extracellular signal-regulated kinase (ERK) kinase at two phosphorylation sites, Ser79 and Ser209, where consensus ERK phosphorylation site sequences, which are highly conserved in many species, were present. Ser209 phosphorylation by ERK kinase seemed to be critically important for cancer cell growth [11]. Furthermore, CDCA5 expression in peripheral $\mathrm{T}$ cells as well as tumor cells was associated with poor survival in lung cancer patients [10].

ERK is a member of the mitogen-activated protein kinase (MAPK) family that regulates critical phases of cell growth, including proliferation, differentiation, transcription regulation, and development [14-16]. It is well known that MAPKs play pivotal roles in carcinogenesis [17] and that the MAPK pathway is a key downstream signaling pathway regulated by epidermal growth factor receptor (EGFR) signaling in a number of cancers $[14,15]$. Up to $90 \%$ of head and neck squamous cell carcinomas (HNSCC), including OSCC, are known to overexpress EGFR and this leads to excessive activation of the EGFR signaling pathway [18, 19]. Activation of EGFR-Raf-MAPK/ERK kinase-ERK signaling has been reported in several cancers, including HNSCC, and has led to the discovery of novel anticancer drugs. Recently, we have been able to use the anti-EGFR monoclonal antibody, cetuximab, to treat HNSCC patients. Compared with platinum-fluorouracil (PF) chemotherapy alone, cetuximab plus PF chemotherapy improved overall survival and progression-free survival in patients with recurrent or metastatic $\mathrm{HNSCC}$, especially in OSCC patients [20]. Therefore, targeting molecules associated with ERK signaling, such as CDCA5, seems to be an appropriate approach for the treatment of OSCC.

In this study, we have demonstrated the overexpression of CDCA5 in OSCC, as well as a clinically significant correlation between CDCA5 expression and patient survival. Furthermore, we have demonstrated that targeting CDCA5 using RNA interference (RNAi) inhibited the growth of human OSCC cells both in vitro and in vivo. These results raise the possibility that CDCA5 is a novel therapeutic target for OSCC. However, at present no CDCA5-targeted drugs are available.

Our study has also demonstrated the successful transfection of tumor cell xenografts with siRNA complexed with atelocollagen [6, 21]. Atelocollagenmediated siRNA delivery has been reported to be effective in gene silencing following either local injection directly into tumors or intravenous systemic injection. This is because siRNA complexed with atelocollagen is resistant to nuclease, so that siRNA can efficiently reach a target site in vivo, without being degraded by nuclease, when combined with an appropriate concentration of atelocollagen [22, 23]. In addition, our recent studies have shown that atelocollagen-mediated, systemic administration of siRNAs specific for the androgen receptor and three Akt isoforms resulted in significant growth inhibition of human prostate cancer in nude mice, without severe side effects such as lung, liver, or renal damage $[24,25]$. These results suggest that nucleic acidbased drugs, such as atelocollagen-complexed siRNA, may provide novel therapeutic opportunities for human malignancies, with minimal risks of adverse events.

In summary, CDCA5 is likely to play a significant role in OSCC progression, so that targeting CDCA5 may be a potentially useful therapeutic approach for patients with OSCC.

\section{MATERIALS AND METHODS}

\section{Cells and cell culture}

We used four human OSCC cell lines, GFP-SAS [26], Ca9-22, HSC2, and HSC3, and an immortalized human non-neoplastic keratinocyte cell line, HaCaT, as previously described [27, 28]. All cell lines were maintained in Dulbecco's modified Eagle's medium (DMEM; Wako, Osaka, Japan) supplemented with 10\% fetal bovine serum (FBS; Biosource Camarillo, CA, USA), $100 \mathrm{U} / \mathrm{ml}$ penicillin, and $100 \mu \mathrm{g} / \mathrm{ml}$ streptomycin (Wako), referred to here as complete medium.

Primary cell cultures were established from OSCC tumors harvested from patients. Tumor tissue was surgically excised and rinsed several times with complete medium. Each tissue sample was cut into small fragments and dissociated by treatment with $0.1 \%$ collagenase (Wako) at $37^{\circ} \mathrm{C}$ for $2 \mathrm{~h}$. The cell suspension was filtered through a $70 \mu \mathrm{m}$ nylon mesh cell strainer (BD, Franklin Lakes, NJ, USA). The cells were collected by centrifugation, resuspended in keratinocyte serumfree medium (K-SFM; Life Technologies, Carlsbad, CA, USA), and seeded onto plastic dishes. In K-SFM, tumor cells could continue to grow but not stromal and 
immune cells. All cells were grown in an incubator with a humidified atmosphere of $95 \%$ air and $5 \% \mathrm{CO}_{2}$ at $37^{\circ} \mathrm{C}$.

\section{Samples from patients}

Twenty OSCCs with the adjacent normal tissue and 80 paraffin-embedded OSCC samples were obtained at the Ehime University Hospital between December 2001 and July 2012. Four primary cell cultures were derived from OSCCs from the lower gingiva and a lymph node metastasis (from a 55 year-old male, T4N2bM0), the lower gingiva (from a 80 year-old female, T4N1M0), and a skin metastasis (from a 61 year-old male, rT0N0M1). The Institutional Review Board (IRB) at Ehime University Hospital approved this study.

\section{qRT-PCR}

Total RNA was extracted by lysing the cells or tissue using ISOGEN (NipponGene, Tokyo, Japan). Tissue samples were homogenized in $1.0 \mathrm{ml}$ of ISOGEN using a TissueLyser (Qiagen, Valencia, CA, USA). The relative quantification of mRNA levels used the comparative threshold cycle (CT) method $(\Delta \Delta \mathrm{CT}$ method), carried out by qRT-PCR using the SYBR $\mathbb{R}$ system. Hydroxymethylbilane synthase (HMBS) was used as internal controls. PCR amplification was carried out in $10 \mu \mathrm{l}$ final reaction mixtures containing $5 \mu \mathrm{l} 2 \mathrm{x}$ One Step SYBR ${ }^{\circledR}$ RT-PCR Buffer 4, $0.4 \mu$ l PrimeScript ${ }^{\circledR}$ One Step Enzyme Mix 2 (Takara, Otsu, Japan), $0.4 \mu$ forward primer $(10 \mu \mathrm{M}), 0.4 \mu \mathrm{l}$ reverse primer $(10 \mu \mathrm{M}), 0.2 \mu \mathrm{l}$ ROX reference Dye II (x 50), $2.6 \mu$ RNase-free $\mathrm{dH}_{2} \mathrm{O}$, and $1 \mu \mathrm{l}$ total RNA $(100 \mathrm{ng} / \mu \mathrm{l})$. The sequences of the primers used were as follows: human CDCA5, forward 5'-ATC CAC CTC GCA GGA GCC CTA-3' and reverse 5'-CTC TCC TTC CTT GGA GCT GGA CT-3'; human HMBS, forward 5'-CAT GCA GGC TAC CAT CCA TGT-3' and reverse 5'-GTT AGC AGT GAT GCC TAC CAA-3'. For analyzing tissue samples from mice, we used the TaqMan ${ }^{\circledR}$ system. RT-PCR was performed in a $10 \mu \mathrm{l}$ final reaction mixture containing $5 \mu 12 \times$ Quantitect RT-PCR Master Mix, $0.1 \mu$ l Quantitect RT mix (Qiagen), $0.5 \mu \mathrm{l} \mathrm{TaqMan}^{\circledR}$ probe and primers (Life Technologies), and $100 \mathrm{ng}$ total RNA. The TaqMan ${ }^{\circledR}$ probe and primers for mouse ISGF-3 $\gamma$, OAS2, MX1 and HMBS were purchased from Life Technologies. The thermal-cycling conditions were reverse transcription at $42^{\circ} \mathrm{C}$ for $5 \mathrm{~min}$ and $95^{\circ} \mathrm{C}$ for $10 \mathrm{~s}$, followed by 40 cycles at $95^{\circ} \mathrm{C}$ for 5 $\mathrm{s}$ and $60^{\circ} \mathrm{C}$ for $30 \mathrm{~s}$. SYBR $\AA$ Green I or $5^{\prime}$-fluorescent reporter dye fluorescence was detected with $\mathrm{ViiA}^{\mathrm{TM}} 7$ (Life Technologies).

\section{Western blot analysis}

Cells $\left(5 \times 10^{5}\right.$ for GFP-SAS, Ca9-22, HSC2, and HSC3) transfected with siRNAs were grown in monolayers for $48 \mathrm{~h}$ and then lysed in $0.5 \mathrm{M}$ EDTA (Dojindo, Kumamoto, Japan) and 1\% NP-40 (Nacalai Tesque, Kyoto Japan) in phosphate-buffered saline (PBS; Wako) containing a protease inhibitor cocktail and a phosphatase inhibitor (Roche Diagnostics, Basel, Switzerland). The samples were centrifuged at 15,000 $\mathrm{g}$ for $15 \mathrm{~min}$ at $4^{\circ} \mathrm{C}$ and the supernatants were electrophoresed on SDS-polyacrylamide gels and then transferred to polyvinylidene difluoride membranes (Millipore, Bedford, MA, USA). The membranes were blocked with 5\% nonfat dried milk (Wako) in $1 \times$ TBS-T (25 mM Tris- $\mathrm{HCl}$, $125 \mathrm{mM} \mathrm{NaCl}$, and 0.1\% Tween 20 (Sigma-Aldrich, St. Louis, MO, USA)) for $1 \mathrm{~h}$ at room temperature. They were then probed with polyclonal rabbit anti-CDCA5 antibody (Atlas Antibodies, Stockholm, Sweden; diluted at 1:500), monoclonal mouse anti- $\beta$-tubulin antibody (BD; diluted at 1:1000), or polyclonal goat anti-actin antibody (Santa Cruz Biotechnology, Dallas, TX, USA; diluted at $1: 1000$ ) in 5\% non-fat dried milk in $1 \times$ TBS-T for $1 \mathrm{~h}$ at room temperature, followed by treatment with horseradish peroxidase-conjugated secondary antibodies against rabbit, mouse (GE Healthcare, Buckinghamshire, UK), or goat (SouthernBiotech, Birmingham, AL, USA) $\mathrm{IgG}$ for $1 \mathrm{~h}$ at room temperature. The immune complexes were visualized using enhanced chemiluminescence (ECL) Prime Western Blotting Detection Reagent (GE Healthcare). The density of visualized immune complexes was digitized using a RAS3000 imaging system (Fujifilm, Tokyo, Japan).

\section{Transfection with synthetic siRNAs}

We used two siCDCA5. Synthetic siCDCA5-1 was purchased from COSMO BIO Co., Ltd. (Tokyo, Japan) with the sequence: sense 5'-CGC AGG AGC CCU AGG AUU UTT-3' and antisense 5'-AAA UCC UAG GGC UCC UGC GTT-3'. The second sequence, siCDCA5-2, was designed by siDirect (http://sidirect2.rnai.jp): sense 5'-UCA AAC UCG GCA UUC AUG GTT -3' and antisense 5'-UGA UCC AAG AAG UAA GUU CTT-3'. Another synthetic siNT was used as a negative control: sense 5'-UAC GUA CUA UCG CGC GGA UTT-3' and antisense 5'-AUC CGC GCG ATA GUA CGU ATT3'. Transfections used Lipofectamine RNAiMAX (Life Technologies) mixed with $10 \mathrm{nM}$ siRNAs for Western blotting and cell proliferation assays. 


\section{Cell growth assay}

Cells were seeded into 96-well plates, using $2 \times$ $10^{3} /$ well for GFP-SAS and $3 \times 10^{3} /$ well for HSC2, HSC3, and $\mathrm{Ca} 9-22$, in complete medium with $10 \mathrm{nM}$ synthetic siRNAs and $0.2 \%$ Lipofectamine RNAiMAX in a final volume of $100 \mu \mathrm{l}$. After $72 \mathrm{~h}$, cell growth was evaluated using WST-8 assays (Cell counting Kit-8; Dojindo).

\section{Invasion assay}

The cell invasion was measured using a Corning ${ }^{\circledR}$ BioCoat $^{\mathrm{TM}}$ FluoroBlok ${ }^{\mathrm{TM}}$ 24-Multiwell Insert System (Corning, Corning, NY, USA). GFP-SAS cells were treated with siRNAs for $24 \mathrm{~h}$, after which they were trypsinized, counted, and normalized for cell number between treatments. Cells $\left(1 \times 10^{5}\right)$ in serum-free DMEM were placed in an insert made of polycarbonate membrane with $8-\mu \mathrm{m}$ pores and precoated with basement membrane matrix. The outer chamber was filled with $0.5 \mathrm{ml}$ of DMEM containing 5\% FBS. The plate was incubated at $37^{\circ} \mathrm{C}$ for 24 hours. The fluorescence of the invaded cells was read at 485/535 nm with ARVO $^{\text {TM }}$ MX 1420 Multilabel Counter (PerkinElmer, Waltham, MA, USA).

\section{Flow cytometry}

Human OSCC cells were transfected with $10 \mathrm{nM}$ synthetic siCDCA5 with Lipofectamine RNAiMAX for $48 \mathrm{~h}$. After incubation, cells were detached with trypsin at $37^{\circ} \mathrm{C}$, washed twice with cold PBS, and resuspended in $10 \mathrm{ml}$ ice cold $70 \%$ ethanol for $2 \mathrm{~h}$. The prepared cells were washed twice with PBS and then incubated at $37^{\circ} \mathrm{C}$ for $15 \mathrm{~min}$ in $0.25 \mathrm{mg} / \mathrm{ml}$ bovine pancreas ribonuclease A (Sigma-Aldrich), using $1 \mathrm{ml}$ per $1 \times 10^{6}$ cells. The suspensions were stained with propidium iodide solution (Sigma-Aldrich) at $4^{\circ} \mathrm{C}$ for $30 \mathrm{~min}$ and analyzed using an EPICS XL-MCl flow cytometer (Beckman Coulter, Fullerton, CA, USA).

\section{Xenograft model and tumor therapy}

GFP-SAS cells were complexed with Matrigel $^{\circledR}$ (BD) using $2 \times 10^{6}$ cells per $100 \mu \mathrm{l}$ aliquot and injected subcutaneously at two sites in the flanks of male athymic nude mice (CLEA Japan, Tokyo, Japan). One week later, tumor-bearing nude mice were randomly divided into two treatment groups, receiving either siCDCA5-1 or siGFP with the sequence: sense 5'-CUA CAA CAG CCA CAA CGU CTT-3' and antisense 5'-GAC GUU GUG GCU GUU GUA GTT - 3 '. The siRNAs were used at a final concentration of $20 \mu \mathrm{M}$ in atelocollagen (AteloGene; Koken, Tokyo, Japan). These complexes were injected into the subcutaneous spaces around the tumors every 3 days.
Tumor diameters were measured at regular intervals using digital calipers and tumor volumes $\left(\mathrm{mm}^{3}\right)$ were calculated using the formula: length $\times$ width $\times$ height $\times 0.523$. Three mice were used in each group. Thirteen days after the first administration of siRNAs, the GFP-SAS xenografts were dissected and the CDCA5 protein expression levels were determined by western blotting. The animal studies were approved by the Ehime University animal care committee.

\section{Immunohistochemistry}

The surgically resected OSCC specimens were fixed in 10\% phosphate-buffered formalin and embedded in paraffin. A series of $4 \mu \mathrm{m}$ thick tissue sections were prepared from each sample. Immunohistochemistry was performed using the avidin-biotin-peroxidase complex method. Briefly, the deparaffinized sections were incubated with $0.3 \% \mathrm{H}_{2} \mathrm{O}_{2}$ in distilled water for $5 \mathrm{~min}$ to block endogenous peroxidase activity, and treated at $121^{\circ} \mathrm{C}$ in an autoclave for $20 \mathrm{~min}$ in $10 \mathrm{mM}$ citrate buffer (pH 6.0) to regenerate epitopes. The sections were then incubated for $30 \mathrm{~min}$ at room temperature with antiCDCA5 antibody (diluted 1:50; Atlas Antibodies). After washing, the sections were overlaid with biotinylated antirabbit antibody (Vector Laboratories, Burlingame, CA, USA) at room temperature for $30 \mathrm{~min}$, washed in TBS-T, and then labeled with streptavidin-peroxidase complex (Vector Laboratories). The sections were counterstained with hematoxylin, dehydrated with ethanol, treated with xylene, and mounted in synthetic resin. We selected three hot spots for measuring labeled cells using a BIOREVO BZ-9000 microscope (Keyence, Osaka, Japan) and the prevalence of CDCA5 positive cells were calculated using Dynamic cell count BZ-H1C software (Keyence) [29]. Immunohistochemical staining for CDCA5 protein was categorized as high or low by the median value of positive rate of tumor cells.

\section{Statistical analysis}

Student's t-test was used to determine the significance of differences between groups. Differences in patient survival were determined using the log-rank test, with $p$ values $<0.05$ considered statistically significant. Statistical analyses were performed using GraphPad Prism software, version 5.04 (GraphPad Software, San Diego, CA, USA).

\section{FUNDING}

This work was supported by Grants-in-Aid for Young Scientists (A) 17689057 and Young Scientists (B) 26861727 from the Japan Society for the Promotion of Science. 


\section{CONFLICTS OF INTEREST}

The authors have no conflicts of interest to declare.

\section{REFERENCES}

1. Ferlay J, Shin HR, Bray F, Forman D, Mathers C, Parkin DM. Estimates of worldwide burden of cancer in 2008: GLOBOCAN 2008. International Journal of Cancer. 2010; 127: 2893-2917.

2. Gupta S, Kong W, Peng Y, Miao Q, Mackillop WJ. Temporal trends in the incidence and survival of cancers of the upper aerodigestive tract in Ontario and the United States. International Journal of Cancer. 2009; 125: 2159 2165 .

3. Weinstein IB. Cancer. Addiction to oncogenes - the Achilles heal of cancer. Science. 2002; 297: 63-64.

4. Druker BJ, Guilhot F, O’Brien SG, Gathmann I, Kantarjian H, Gattermann N, Deininger MW, Silver RT, Goldman JM, Stone RM, Cervantes F, Hochhaus A, Powell BL, et al; IRIS Investigators. Five-year follow-up of patients receiving imatinib for chronic myeloid leukemia. The New England Journal of Medicine. 2006; 335: 2408-2417.

5. Tural D, Kilickap S. First-line crizotinib in ALK-positive lung cancer. The New England Journal of Medicine. 2015; 372: 781-782.

6. Tanaka H, Nakashiro K, Iwamoto K, Tokuzen N, Fujita Y, Shirakawa R, Oka R, Goda H, Hamakawa H. Targeting Aurora kinase A suppresses the growth of human oral squamous cell carcinoma cells in vitro and in vivo. Oral Oncology. 2013; 49: 551-559.

7. Rankin S, Ayad NG, Kirschner MW. Sororin, a substrate of the anaphase-promoting complex, is required for sister chromatid cohesion in vertebrates. Molecular Cell. 2005; 18: $185-200$.

8. Schmitz J, Watrin E, Lénárt P, Mechtler K, Peters JM. Sororin is required for stable binding of cohesin to chromatin and for sister chromatid cohesion in interphase. Current Biology. 2007; 17: 630-636.

9. Zhang N, Pati D. Sororin is a master regulator of sister chromatid cohesion and separation. Cell Cycle. 2012; 11: 2073-2083.

10. Showe MK, Kossenkov AV, Showe LC. The peripheral immune response and lung cancer prognosis. Oncoimmunology. 2012; 1: 1414-1416.

11. Nguyen MH, Koinuma J, Ueda K, Ito T, Tsuchiya E, Nakamura Y, Daigo Y. Phosphorylation and activation of cell division cycle associated 5 by mitogen-activated protein kinase play a crucial role in human lung carcinogenesis. Cancer Research. 2010; 70: 5337-5347.

12. Bidkhori G, Narimani Z, Hosseini Ashtiani S, Moeini A, Nowzari-Dalini A, Masoudi-Nejad A. Reconstruction of an integrated genome-scale co-expression network reveals key modules involved in lung adenocarcinoma. PLoS One.
2013; 8: e67552.

13. Chang IW, Lin VC, He HL, Hsu CT, Li CC, Wu WJ, Huang $\mathrm{CN}, \mathrm{Wu} \mathrm{TF}, \mathrm{Li} \mathrm{CF}$. CDCA5 overexpression is an indicator of poor prognosis in patients with urothelial carcinomas of the upper urinary tract and urinary bladder. American Journal of Translational Research. 2015; 7: 710-722.

14. Roux PP, Blenis J. ERK and p38 MAPK-activated protein kinases: a family of protein kinases with diverse biological functions. Microbiology and Molecular Biology Reviews. 2004; 68: 320-344.

15. Chang L, Karin M. Mammalian MAP kinase signalling cascades. Nature. 2001; 410: 37-40.

16. Aguzzi A, Maggioni D, Nicolini G, Tredici G, Gaini RM, Garavello W. MAP kinase modulation in squamous cell carcinoma of the oral cavity. Anticancer Research. 2009; 29: 303-308.

17. Mansour SJ, Matten WT, Hermann AS, Candia JM, Rong S, Fukasawa K, Vande Woude GF, Ahn NG. Transformation of mammalian cells by constitutively active MAP kinase kinase. Science. 1994; 265: 966-970.

18. Temam S, Kawaguchi H, El-Naggar AK, Jelinek J, Tang H, Liu DD, Lang W, Issa JP, Lee JJ, Mao L. Epidermal growth factor receptor copy number alterations correlate with poor clinical outcome in patients with head and neck squamous cancer. Journal of Clinical Oncology. 2007; 25: 2164-2170.

19. Kalyankrishna S, Grandis JR. Epidermal growth factor receptor biology in head and neck cancer. Journal of Clinical Oncology. 2006; 24: 2666-2672.

20. Vermorken JB, Mesia R, Rivera F, Remenar E, Kawecki A, Rottey S, Erfan J, Zabolotnyy D, Kienzer HR, Cupissol D, Peyrade F, Benasso M, Vynnychenko I, et al. Platinumbased chemotherapy plus cetuximab in head and neck cancer. The New England Journal of Medicine. 2008; 359: 1116-1127.

21. Mu P, Nagahara S, Makita N, Tarumi Y, Kadomatsu K, Takei Y. Systemic delivery of siRNA specific to tumor mediated by atelocollagen: combined therapy using siRNA targeting $\mathrm{Bcl}-\mathrm{xL}$ and cisplatin against prostate cancer. International Journal of Cancer. 2008; 125: 2978-2990.

22. Ochiya T, Takahama Y, Nagahara S, Sumita Y, Hisada A, Itoh H, Nagai Y, Terada M. New delivery system for plasmid DNA in vivo using atelocollagen as a carrier material: the Minipellet. Nature Medicine. 1999; 5: 707710 .

23. Minakuchi Y, Takeshita F, Kosaka N, Sasaki H, Yamamoto Y, Kouno M, Honma K, Nagahara S, Hanai K, Sano A, Kato T, Terada M, Ochiya T. Atelocollagen-mediated synthetic small interfering RNA delivery for effective gene silencing in vitro and in vivo. Nucleic Acids Research. 2004; 32: e109.

24. Azuma K, Nakashiro K, Sasaki T, Goda H, Onodera J, Tanji N, Yokoyama M, Hamakawa H. Anti-tumor effect of small interfering RNA targeting the androgen receptor in human androgen-independent prostate cancer cells. Biochemical 
and Biophysical Research Communications. 2010; 391: 1075-1079.

25. Sasaki T, Nakashiro K, Tanaka H, Azuma K, Goda H, Hara S, Onodera J, Fujimoto I, Tanji N, Yokoyama M, Hamakawa H. Knockdown of Akt isoforms by RNA silencing suppresses the growth of human prostate cancer cells in vitro and in vivo. Biochemical and Biophysical Research Communications. 2010; 399: 79-83.

26. Shintani S, Mihara M, Nakahara Y, Aida T, Tachikawa T, Hamakawa H. Lymph node metastasis of oral cancer visualized in live tissue by green fluorescent protein expression. Oral Oncology. 2002; 38: 664-669.

27. Klosek SK, Nakashiro K, Hara S, Goda H, Hamakawa H. Stat3 as a molecular target in RNA interference-based treatment of oral squamous cell carcinoma. Oncology Reports. 2008; 20: 873-878.

28. Shintani S, Hamakawa $H$, Nakashiro $K$, Shirota $T$, Hatori M, Tanaka M, Kuroshita Y, Kurokawa Y. Friend leukaemia insertion (Fli)-1 is a prediction marker candidate for radiotherapy resistant oral squamous cell carcinoma. International Journal of Oral and Maxillofacial Surgery. 2010; 39: 1115-1119.

29. Kan H, Kimura Y, Hyogo H, Fukuhara T, Fujino H, Naeshiro N, Honda Y, Kawaoka T, Tsuge M, Hiramatsu A, Imamura $\mathrm{M}$, Kawakami $\mathrm{Y}$, Aikata $\mathrm{H}$, et al. Non-invasive assessment of liver steatosis in non-alcoholic fatty liver disease. Hepatology Research. 2014; 44: E420-427. 